\title{
A Clinical Study of Displacement of Lens
}

\author{
Dr. D. BhimaSankarBabu M.S ${ }^{1,}$ Dr. M.Vijayaleela M.S \\ ${ }^{1}$ Assosiate Professor Of Ophthalmology Sarojini Devi Eye Hospital. \\ ${ }^{2}$ Assosiate Professor Of Ophthalmology Nizamabad
}

\begin{abstract}
A total of 52 cases of displacement of lens are studied from out patients Sarojini Devi Eye Hospital, Hyderabad with special reference to the cause of dislocation, associated ocular complications and management. The study was conducted from november 2014 to November 2016.Among the 52 cases studied 29 males and 23 females are present. The incidence is more in males probably due to more exposure to trauma in view of the outdoor life and occupation undertaken by males..Age wise distribution showed maximum incidence in theseventh decade of life. Out of 52 patients 16 patients are from this group constituting $30.7 \%$ of total incidence.The next common age group being the sixth decade with total of 13 cases falling in this
\end{abstract}

Type Of Study:Retrospective study

Place Of Study: Sarojini Devi Eye Hospital

Aims And Objectives Of The Study

1. To study the etiology, predisposing factors that lead to displacement of lens, clinical features varying with its position, and complications of displacement of lens.

2. The objectives of the study is to contemplate different modalities of treatment like masterly inactivity, optical correction and surgical correction which includes small incision cataractsurgery with posterior chamber intra ocular lens implantation, scleral fixated intra ocular lens implantation, anterior chamber intra ocular lens implantation to improve vision.

Inclusion Criteria:

1.All age groups with displaced lens

2.Patients with history of trauma.

Exclusion Criteria

1.Those who are not willing to give consent

\section{Introduction}

- The transparency, health and position of the lens are of utmost importance to focus the objects on the retina.

- The lens is devoid of blood vessels and suspended in the intraocular fluid as acluster cells within a capsule.

- Lens and cornea are the two most powerful optical media,responsible for focusing and formation of a precise image of all that the eye surveys.

- Any Alteration in the position of lens leads to many problems optically and also in other issueslikeiris,ciliartbodyvitreous,retina,cornea in response to the displaced lens.

- The lens is suspended by the fibers of the suspensory ligament so that its axis corresponds approximately to the visual line.

- The displacement of lens can be due to a congential defect in the zonule or disease are trauma where by the suspensory apparatus is weakened so that the lens becomes tremulous or subluxated or it is ruptured so that a complete dislocation occurs.

- The displacement of lens continues to be an interesting subject for ophthalmologists world over. Capacious literature about this subject indicates that laudable work has been one on dislocated lens, and its complications and also prevailing controversies.

- According some ophthalmologists an eye containing a displaced lens is prone for uveitis, glaucoma or retinal detachment and advice prophylactic removal

- Another school of thought is that the hazards of removing a displaced lens outweigh the benefits in most instances and hence conservative management.

\section{Materials And Methods}

- The present clinical study of displacement of lens was under taken on patients attending the Sarojinidevi. Eye. Hospital, Hyderabad, during the period November 2014 to November 2016.

- The present study was done with special reference to etiology, clinical features, diagnosis and management of fifty two cases of displacement of lens. 
- Systemic and complete ophthalmic examination in every case and findings are recorded.

- The results of the present study are completely analyzed,relevant conclusions are derived and summarized.

\section{Summary Of Cases}

- A total of 52 cases of displacement of lens are studies from out patients Sarojini Devi Eye Hospital, Hyderabad with special reference to the cause of dislocation, associated ocular complications and management. The study was conducted from november 2014 to November 2016.

- Among the 52 cases studied 29 males and 23 females are present. The incidence is more in males probably due to more exposure to trauma in view of the outdoor life and occupation undertaken by males.Age wise distribution showed maximum incidence in the seventh decade of life.

- Out of 52 patients 16 patients are from this group constituting $30.7 \%$ of total incidence. The next common age group being the sixth decade with total of 13 cases falling in this group,q constituting $25 \%$ of total incidence.

\begin{tabular}{|l|l|l|l|l|l|l|l|l|}
\hline $\begin{array}{l}\text { Age in Group in } \\
\text { years }\end{array}$ & $0-10$ & $11-20$ & $21-30$ & $31-40$ & $41-50$ & $51-60$ & $61-70$ & $71-80$ \\
\hline Number of cases & 0 & 7 & 6 & 2 & 7 & 13 & 16 & 1 \\
\hline
\end{tabular}

- Patients above 50 years of age are most affected pointing that weakness of zonules is an age -related change resulting more incidence of displacement of lens in patients above fifty years of age.Aetiologically displacement of lens is classified into three categories)

1.Congenital

2.Traumatic

3. Consecutive or spontaneous due to intraocular disease giving rise to mechanical stretching, inflammatory disintegration or degeneration of zonules. In the present series spontaneous displacement of lens consecutive to intraocular disease is mainly responsible for displacement with 31 of total 52 cases accounting for $59.6 \%$ of cases.

- All of these cases are associated with different types of cataract additions 10 cases among these are also related to pseudo exfoliation. Trauma is the second factor of responsible for 16 cases. Remaining 5 cases were due to congenital causes.

- In hypermature cataract degenerative changes of zonules is common and it is stretched due to shrinkage of lens, thus resulting in spontaneous displacement but incidence of some insignificant trauma resulting in dislocation could not be ruled out in these cases many standard works on the displacement of lens placed trauma in the highest bracket as far as the factor responsible for displacement is concerned.

- But in the present series spontaneous; displacement of lens consecutive to other intraocular disease is appeared as main cause responsible for displacement.

\begin{tabular}{|l|l|l|l|}
\hline & Congenital(\%) & Consecutive(\%) & Traumatic(\%) \\
\hline Mooren (1984) & 10.8 & 31.9 & 57.3 \\
\hline Grob (1901) & 14.4 & 56.8 & 28.8 \\
\hline Ringelhan and Elschnig(1931) & 12.9 & 56.2 & 30.9 \\
\hline Knowblock(1931) & 17.1 & 62.3 & 20.6 \\
\hline Mc.Donald and Purnell(1951) & 35 & 47 & 18 \\
\hline Nirankari and Chaddah(1967) & 18 & 22 & 60 \\
\hline Present Series & 7.6 & 30.7 & 61.5 \\
\hline
\end{tabular}

- Pseudoexfoliation is present in 10 patients out of 31 cases of spontaneous displacement of lens accounting $19.2 \%$ of total cases of displacement of lens.

- In all congenital cases the displcement of lens is bilateral but it is rare in traumatic and consecutive displacement.

- Sex distribution unilateral displacement in the three aetiological type of displacement of lens is shown in the following tabular form.

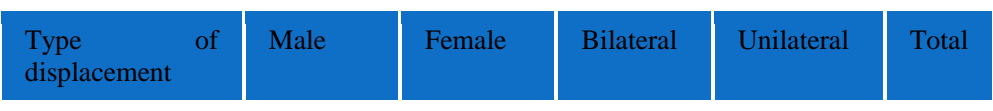




\begin{tabular}{|l|l|l|l|l|l|}
\hline Congenital & 3 & 2 & 5 & Nil & 5 \\
\hline Consecutive & 20 & 11 & Nil & 31 & 31 \\
\hline Traumatic & 10 & 6 & Nil & 16 & 16 \\
\hline
\end{tabular}

- Of the total 52 cases of displacement 37 cases are subluxation and 15 cases are dislocation.

- In 9 cases dislocation is anterior and in 6 cases dislocation is posterior.

- In anterior dislocation the lens is always found in anterior chamber and out of these 6 cases showed rise in intraocular pressure.

- In three cases there is no rise of intraocular pressure when first seen and immediate surgical intervention by extraction prevented rise in pressure.

- State of lens at time of displacement presented varied picture from hypermature cataract to clear lens.

\begin{tabular}{|l|l|l|}
\hline State of lens & No.of cases Recorded & Percentage \\
\hline Transparent & 4 & 7.69 \\
\hline Hypermature cataract & 20 & 38.46 \\
\hline Mature cataract & 14 & 26.92 \\
\hline Brown cataract & 10 & 19.23 \\
\hline Immature cataract & 4 & 7.69 \\
\hline
\end{tabular}

\section{Analysis Of Treatment And Results Obtained}

In anterior dislocation of lens into anterior chamber irrespective of the condition of lens and incidence of secondary glaucoma extraction of lens was undertaken to prevent forther complication like secondary glaucoma severe iridocyclitis corneal degeneration and migration of lens into posterior chamber. Wherever there is rise of intraocular pressure medical treatment is instituted to reduce intraocular pressure to normal limits and once the tension is under control extraction of lens is proceeded with all precautions.

In posterior dislocation extraction of lens was avoided in majority of cases as the attendant complications like vitreous loss, injury to retina or choroid out weigh the benefit of extraction in cases where there are no other complications like iridocyclitis, secondary glaucoma etc. and eye is quiet, tolerating the displaced lens well, the lens was left alone and with aphakic correction satisfactory results were obtained.

In cases of subluxation, congenital or acquired extraction of lens is undertaken in presence of following indications:

1. To prevent glaucoma

2. To improve vision where the lens is cataractous or has become eccentrically displaced

3. To prevent subluxated lens from becoming totally luxated into vitreous as it may be more difficult to extract such a lens.

The results of treatment are analysed as follows:-

In the 12 cases of dislocation of lens 4 cases were of anteriorly dislocated lens and in 8 cases the lens was displaced posteriorly.

Out of 4 cases of anterior displacement 3 cases presented with anterior dislocation, and one case presented with anterior subluxation.the traumatic anterior subluxation was treated by Small Incision cataract Sugery without IOL implantation. The other anterior dislocations were treated by vectis removal of lens and IOL implantation was deferred. Among these cases in one case postoperative improvement of vision was not satisfactory. The remaining cases showed good post operative result without any complication the visual acuity with correction was $6 / 60$ to $6 / 36$.

In the 8 cases in which the lens was subluxated posteriorly, there were 5 cases of congenital subluxation of which 4 were cases of Marfan's syndrome, 1 was weilMarchesani syndrome cases sclera-sutured posterior chamber IOL was implanted. The visual acuity in postoperative period was 6/36.

In another Marfans's syndrome case only lens extraction was performed because patient was myopic and had useful vision in aphakic eye and was advised for follow up regularly.

\section{Conclusions}


- Displacement is common in aged people particularly beyond fifth decade of life, more so in the sixth and seventh decades and it is most probably due to the weakening of zonules which is an age change.

- It is found to be relatively more common in males due to more exposure to trauma due to to outdoor life and occupations.

- Displacement of a hypermaturecataractous lens is found to be more common.

- Iridocyclitis and secondary glaucoma are most common attendant complications.

- Anteriorly dislocated lens is always extracted after treating the complications.Subluxated lens is also extracted to prevent complete dislocation or for better optical purposes when the lens is cataractous or as a part of treatment of secondary glaucoma and the post-operative results in these categories are uniformly good in cases where intervention is early enough.

- In case of posteriorly dislocated lens selective extraction is resorted and extraction is undertaken where there are impending complications.

- Tradition and convention indicating a conservative approach to the problem of displaced lens with all its attendant complications, march of science with advancement in techniques of surgery with the newly acquired methods and mean to control complications like rise in tension, preoperatively, on the table, and postoperatively, the pendulum is swinging towards surgical intervention and extraction of lens.

- From those series it will be reasonable to conclude that extraction of displaced lens is justified when it is the culprit of complications but where the eye is quite and the displaced lens is tolerated well, it is equally justified to leave it alone, through the saying of health that "once out of its bed the lens becomes a marauder and is in effect a foreign body within the eye" is always worth keeping in mind.

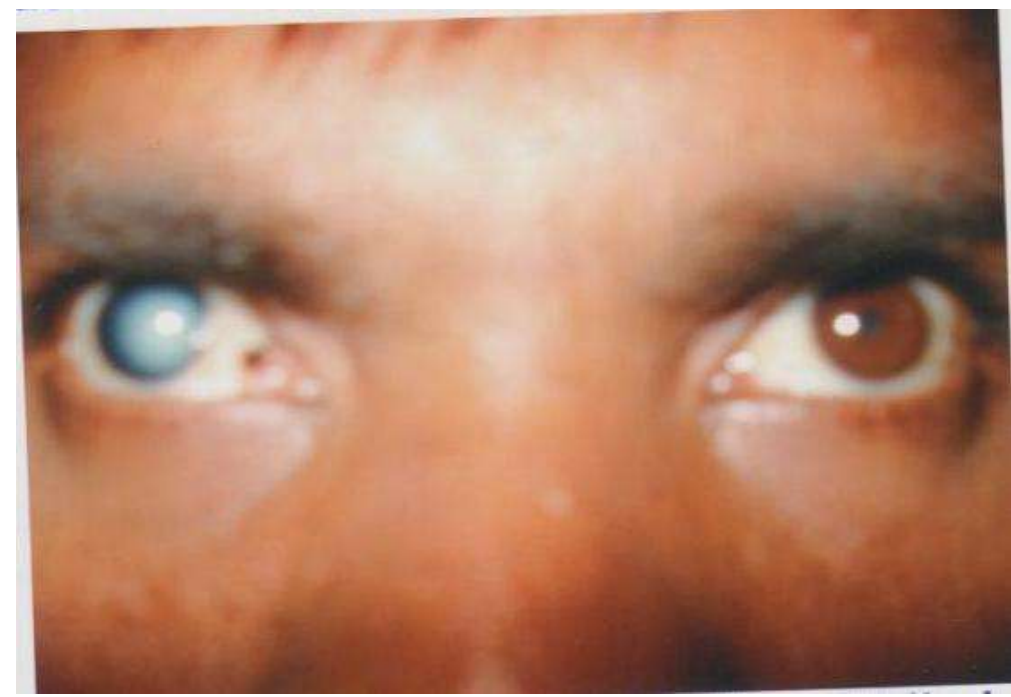

Traumatic anterior dislocation in right eye

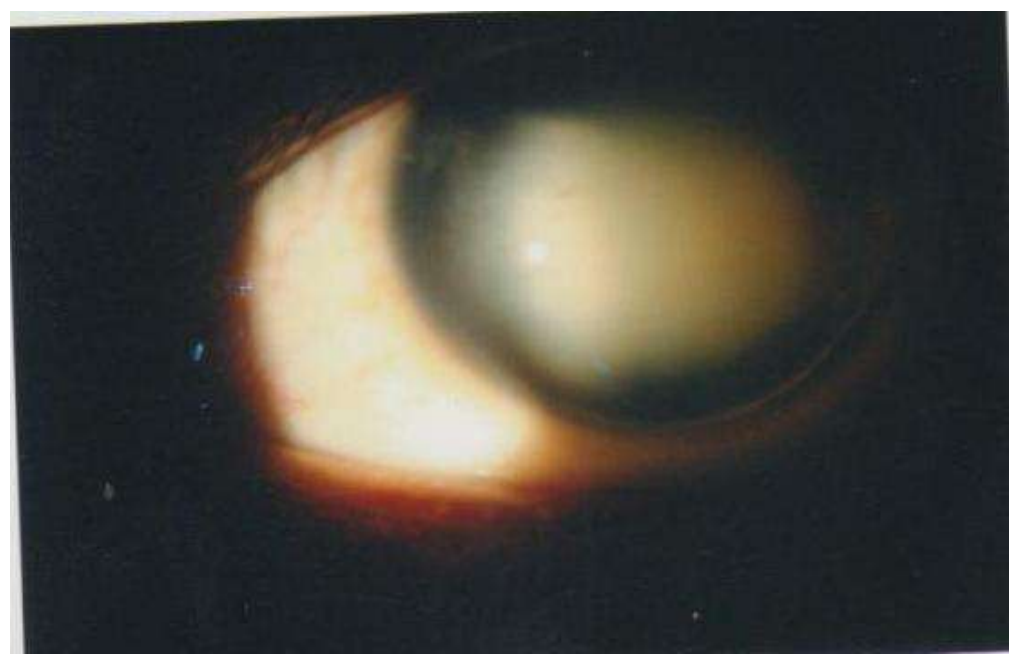

Traumatic anterior dislocation with anirridia in right eye 


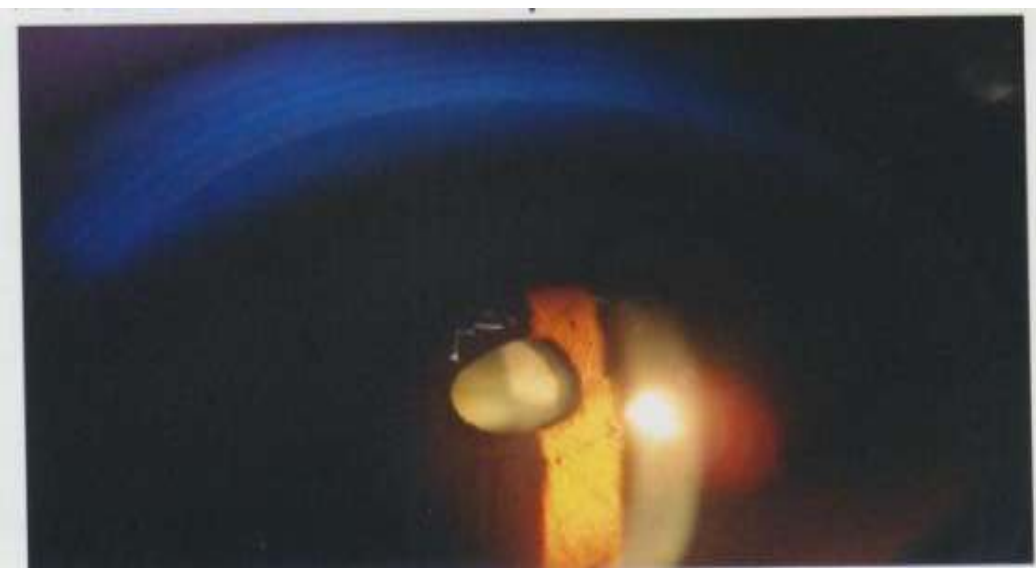

Hyper mature cataract with pseudoexfoliation in left eye

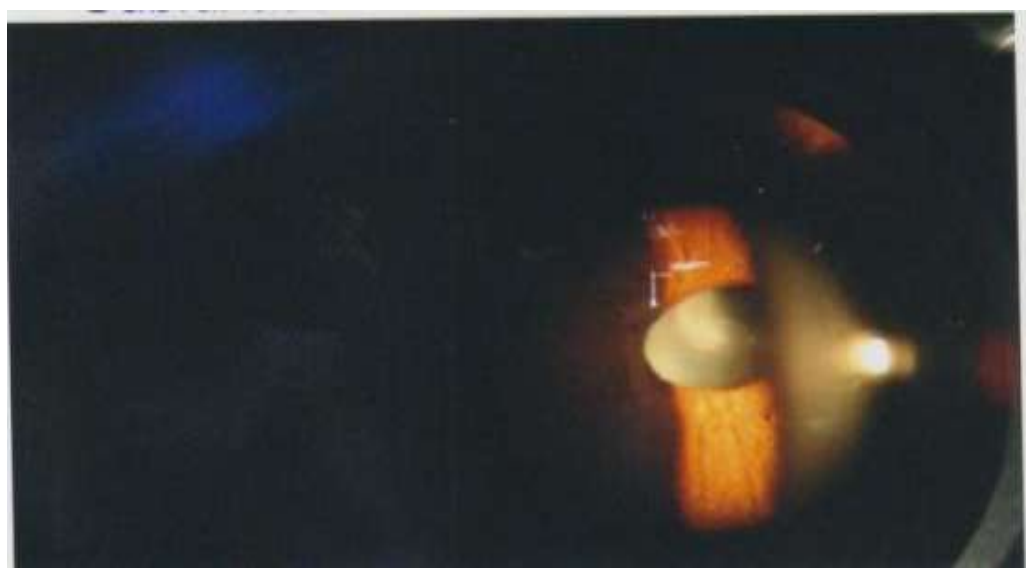

Subluxation of lens with iridodonesis

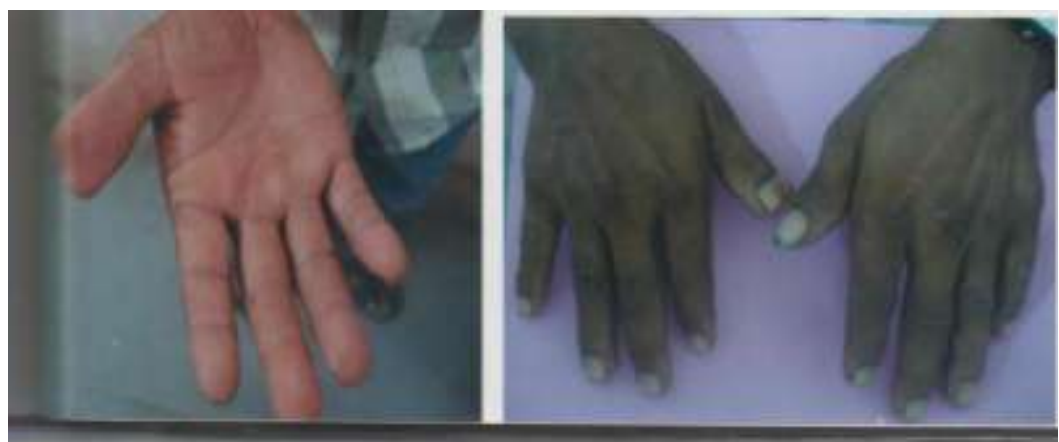

Short and stubby fingers

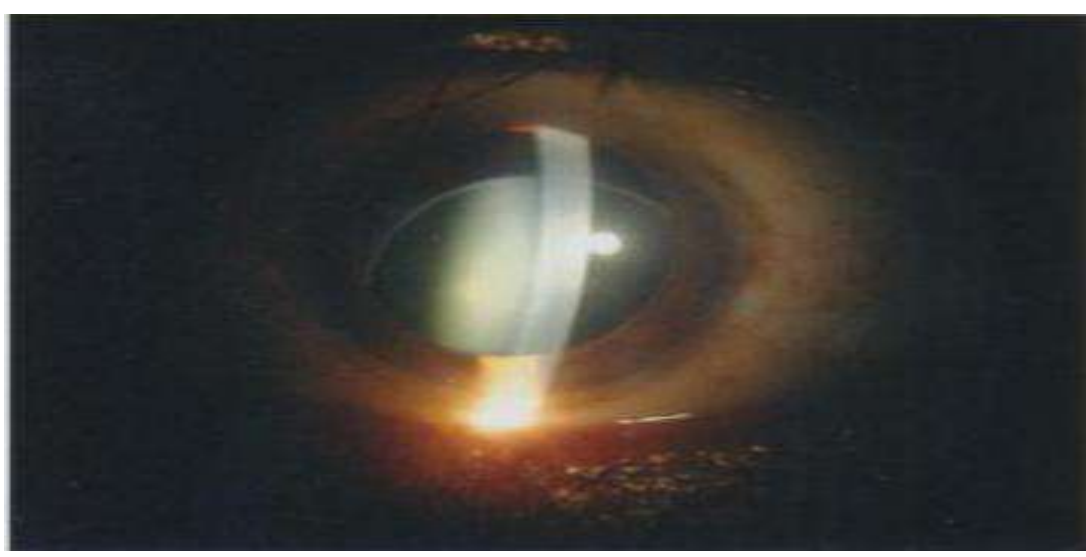

Infero temporal subluxation of cataractous lens in left eye 


\section{Bibliography}

[1]. Adler's Physiology of the eye-sixth edition.

[2]. Norman S. Jaffe, Mark S.Jaffe, Gary F. Jaffe-cataract surgery and its complications $6^{\text {th }}$ edition.

[3]. Eugene wolff's -Anatomy of the eye and orbit $6^{\text {th }}$ edition.

[4]. Frederick H. Theodore-complications after cataract surgery.

[5]. Ida mann-Developmental abnormalities of the eye second edition.

[6]. Mortorn F. Gold berg - Genetic and metabolic eye disease. 